\title{
Electrochemical Reduction Using Glassy Carbon Electrode in Aqueous Medium of a Potential Anti-Chagas Drug: NFOH
}

\author{
M. A. La-Scalea, ${ }^{\mathrm{a}, \mathrm{b}, \mathrm{z}}$ G. H. G. Trossini, ${ }^{\mathrm{b}}$ C. M. S. Menezes, ${ }^{\mathrm{b}, \mathrm{c}}$ M. C. Chung, ${ }^{\mathrm{d}}$ and \\ E. I. Ferreira ${ }^{\text {b }}$ \\ ${ }^{a}$ Departamento de Ciências Exatas e da Terra, Universidade Federal de São Paulo, Diadema, Brazil \\ ${ }^{b}$ Departamento de Farmácia, Faculdade de Ciências Farmacêuticas, Universidade de São Paulo, São Paulo, \\ Brazil \\ ${ }^{c}$ LaSSBio, Faculdade de Farmácia, Universidade Federal do Rio de Janeiro, Rio de Janeiro, Brazil \\ ${ }^{d}$ Departamento de Fármacos e Medicamentos, Faculdade de Ciências Farmacêuticas, Universidade Estadual \\ "Júlio de Mesquita Filho", Araraquara, Brazil
}

\begin{abstract}
Nitrofurazone (NF) presents activity against Chagas' disease, yet it has a high toxicity. Its analog, hydroxymethylnitrofurazone $(\mathrm{NFOH})$, is more potent against Trypanosoma cruzi and much less toxic than the parent drug, NF. The electrochemical reduction of NFOH in an aqueous medium using a glassy carbon electrode (GCE) is presented. By cyclic voltammetry in anacidic medium, one irreversible reduction peak related to hydroxylamine derivative formation was registered, being linearly $\mathrm{pH}$ dependent. However, from $\mathrm{pH}>7$, a reversible reduction peak at a more positive potential appears and corresponds to the formation of a nitro radical anion. The radical-anion kinetic stability was evaluated by $I \mathrm{p}_{\mathrm{a}} / I \mathrm{p}_{\mathrm{c}}$ the current ratio of the $\mathrm{R}-\mathrm{NO}_{2} / \mathrm{R}-\mathrm{NO}_{2}^{\circ-}$ redox couple. The nitro radical anion decays with a second-order rate constant $\left(k_{2}\right)$ of $6.07,2.06$, and $1.44\left(\times 10^{3}\right) \mathrm{L} \mathrm{mol}^{-1} \mathrm{~s}^{-1}$ corresponding to $\mathrm{pH} 8.29,9.29$, and 10.2 , respectively, with a corresponding half-time life $\left(t_{1 / 2}\right)$ of 0.33 , 0.97 , and $1.4 \mathrm{~s}$ for each $\mathrm{pH}$ value. By polishing the GCE surface with diamond powder and comparing with the GCE surface polished with alumina, it is shown that the presence of alumina affects the lifetime of the nitro radical anion. (C) 2009 The Electrochemical Society. [DOI: 10.1149/1.3130082] All rights reserved.
\end{abstract}

Manuscript submitted November 16, 2008; revised manuscript received April 13, 2009. Published May 15, 2009.

Chagas' disease affects about one-quarter of the population in Latin America. Moreover, according to the World Health Organization, approximately 100 million people live under the risk of contracting this parasitosis and 16-18 million people might be infected. ${ }^{1}$ In Brazil, where nearly 6 million people are infected, the main problem concerning treatment is the Trypanosoma cruzi resistance to nifurtimox. As an alternative to this, benznidazole (a 2-nitroimidazole) is the only drug used in Brazil to combat Chagas' disease. Unfortunately, both drugs are effective only in the acute phase of the disease. ${ }^{2}$ Even though, few new compounds have been assayed clinically.

Some new nitroheterocyclic compounds have been proposed as candidate drugs for Chagas' disease chemotherapy, ${ }^{3-6}$ some of which have a trypanocidal action due to their ability to be reduced by flavoproteins generating the nitro radical anion or forming the superoxide and hydrogen peroxide. Consequently, the electron transfer from the radical to the molecular oxygen causes direct or indirect cellular damage, the former by reaction with various biological macromolecules and the latter by generation of the highly reactive hydroxyl radical. ${ }^{3,4}$ The biological action of nitrofurazone (NF) has been reported on $T$. cruzi through trypanothione reductase inhibition, an enzyme found in the parasite rather than in the host. ${ }^{5,7}$

It is generally accepted that the nitro radical anion and hydroxylamine derivative are the main species responsible for some nitroheterocyclic compounds' cytotoxic action. ${ }^{8,9}$ As a result, electrochemical studies can be relevant for the comprehension of the redox cycles involved in these biological processes. In this sense, the differences in the biological activities of the nitroheterocyclic as antimicrobial agents were explained by electrochemical studies, ${ }^{10}$ because significant differences among the reduction potential values $\left(E_{1 / 2}\right)$ of these compounds were registered. Considering Chagas' disease, the voltammetric peak potential values obtained for several nitrofuran analogs do not unequivocally indicate a relationship with their trypanocidal activities, which demonstrates that other factors such as stereochemistry, lipophylicity, diffusion, and kinetics can determine the anti-Chagas action of these kinds of compounds., This indicates that for different biological targets, different physicochemical parameters can set the action of biologically active compounds.

${ }^{\mathrm{z}}$ E-mail: mauro.scalea@unifesp.br
Classically, the kinetic stability of nitro radical anion can be observed by cyclic voltammetry through the one-electron reversible couple due to the redox system $\mathrm{R}-\mathrm{NO}_{2} / \mathrm{R}-\mathrm{NO}_{2}^{--}$. For this, a convenient experimental condition (aprotic medium, mixed solvents, alkaline-pH medium), in which the low disponibility of protons favors the $\mathrm{R}-\mathrm{NO}_{2}^{--}$kinetic stability, is necessary. ${ }^{11}$ Under such conditions, the electrochemical behavior of NF has been extensively studied by using working electrodes such as mercury, ${ }^{12-15}$ gold, ${ }^{14}$ glassy carbon, ${ }^{14,16}$ and boron-doped diamond. ${ }^{17,18}$

The molecular modification has been the most promising approach to introduce drugs in therapeutics and to obtain better drugs. Hydroxymethyl derivatives are generally prodrugs which are more hydrophilic than the parent compound. Generally, NH-acidic drugs such as amides, imides, or ureides are potential targets to $\mathrm{N}$-hydroxymethylation. 5,19

Hydroxymethylnitrofurazone (NFOH), synthesized from NF and formaldehyde (Mannich reaction), ${ }^{5,20}$ has proven to be a potential drug against Chagas' disease. NFOH proved to be about four times more effective against $T$. cruzi than NF, besides being less mutagenic. ${ }^{5}$ However, in a previous work, ${ }^{16}$ the NF and NFOH electrochemical studies have not indicated significant differences in the ease of their reduction. Despite this, we must keep on studying $\mathrm{NFOH}$ due to its importance in establishing the best electrochemical condition which can contribute to a full understanding of its mechanism of action. The existence of a possible additional mechanism of $\mathrm{NFOH}$ action, besides the nitro moiety reduction, was already observed. $^{21}$ Moreover, many researches carried out by our group $^{5,21-23}$ showed that an NFOH derivative is a strong candidate drug against Chagas' disease. Consequently, an NFOH derivative may be used as a reference or a prototype for molecular modification to design better drugs.

We report, in this work, a thorough study of the voltammetric behavior of NFOH (Fig. 1) at a glassy carbon electrode (GCE) in an aqueous medium, with emphasis on the $\mathrm{R}-\mathrm{NO}_{2} / \mathrm{R}-\mathrm{NO}_{2}^{--}$redox couple. The second-order rate constant of the decay of the nitro radical anion and its half-time life have been determined. A brief comparison between metronidazole (MTZ) and chloramphenicol (CFN) voltammetric behaviors by using a carbon-fiber microelectrode is also presented. 
<smiles>NC(=O)N/N=C/c1ccc([N+](=O)[O-])o1</smiles>

nitrofurazone (NF)<smiles>Cc1ncc([N+](=O)[O-])n1CCO</smiles>

metronidazole (MTZ)<smiles>O=C(NCO)N/N=C/c1ccc([N+](=O)[O-])o1</smiles>

hydroxymethylnitrofurazone (NFOH)<smiles>O=C(NC(CO)[C@H](O)c1ccc([N+](=O)[O-])cc1)C(Cl)Cl</smiles>

chloramphenicol (CFN)
Figure 1. Molecular structures of nitrocompounds.

\section{Experimental}

Reagents and solutions. - Stock solutions $(0.01 \mathrm{M})$ of NF (Avocado Co.) and NFOH were prepared through direct dissolution in deionized water and ethanol (1:1) using an ultrasonic bath; MTZ (Rhodia Farma Lda.) and CFN (Sigma Chemical Co.) were prepared by dissolution only in purified water. $\mathrm{pH}$ study was accomplished with a universal buffer (Britton-Robinson) starting from the mixture of phosphoric, acetic, and boric acids with $\mathrm{NaOH} .{ }^{24}$ All solutions were prepared using analytical-grade reagents from Merck and purified water from a Gehaka UV system.

As NFOH is not commercially available, it was synthesized following procedures previously described. ${ }^{5,20}$ The obtained product was monitored using thin-layer chromatography (mobile phase: chloroform-methanol-acetic acid, 85:10:5, v/v/v) and the spectroscopic data corresponding to the one previously reported. ${ }^{25}$

Apparatus and methods.- Cyclic and linear-sweep voltammograms were recorded using an Autolab PGSTAT 30 potentiostat/ galvanostat from Eco-Chimie, Utrecht, Netherlands, coupled to a 15 $\mathrm{mL}$ cell with a three-electrode system: A GCE and carbon-fiber microelectrode as working electrodes, $\mathrm{Ag} / \mathrm{AgCl}$ as a reference electrode, and Pt as an auxiliary electrode. The data acquisition and treatment were performed using the GPES 4.9 program (EcoChimie). Dissolved air was removed from the solutions by $10 \mathrm{~min}$ bubbling with nitrogen. $\mathrm{pH}$ control was carried out by using Metrohm $654 \mathrm{pH}$ meter and the combined-glass electrode at room temperature.

The GCE $(\varnothing=2 \mathrm{~mm}$ Analion, Brazil) was manually and intensely polished with $1 \mu \mathrm{m}$ diamond suspension in spray on Supra metallographic synthetic velvet (granulometry $1 / 4 \mu \mathrm{m}$ ). The carbonfiber microelectrode $(\varnothing=11 \pm 2 \mu \mathrm{m}, \mathrm{BAS})$ was also polished using the same procedure. These treatments were made by using products from Arotec S/A, Brazil. After polishing, both electrodes were rinsed with purified water.

Using the theoretical model, ${ }^{26}$ the $I \mathrm{p}_{\mathrm{Na}} / I \mathrm{p}_{\mathrm{Nc}}$ values were measured at each scan rate and inserted in a work curve to determine the $\omega$ parameter, which incorporates the effects of rate constant, drug concentration, and scan rate. Considering $\alpha \tau=4$, the $\omega$ vs $\tau$ plot results in a linear relationship that can be described by the equation $\omega=k_{2} C_{0} \tau$, where the $k_{2}$ value (the rate constant of the second-order reaction for the nitro radical anion decay) is obtained from this plot slope, $C_{0}$ is the drug concentration, and $\tau=\left(E_{1 / 2}-E_{\lambda}\right) / \nu$. The nitro radical anion stability was calculated by the half-life equation $\left(t_{1 / 2}=1 /\left[\mathrm{R}-\mathrm{NO}_{2}^{-}\right] k_{2}\right)$, assuming that $\left[\mathrm{R}-\mathrm{NO}_{2}^{-}\right]=$drug concentration.

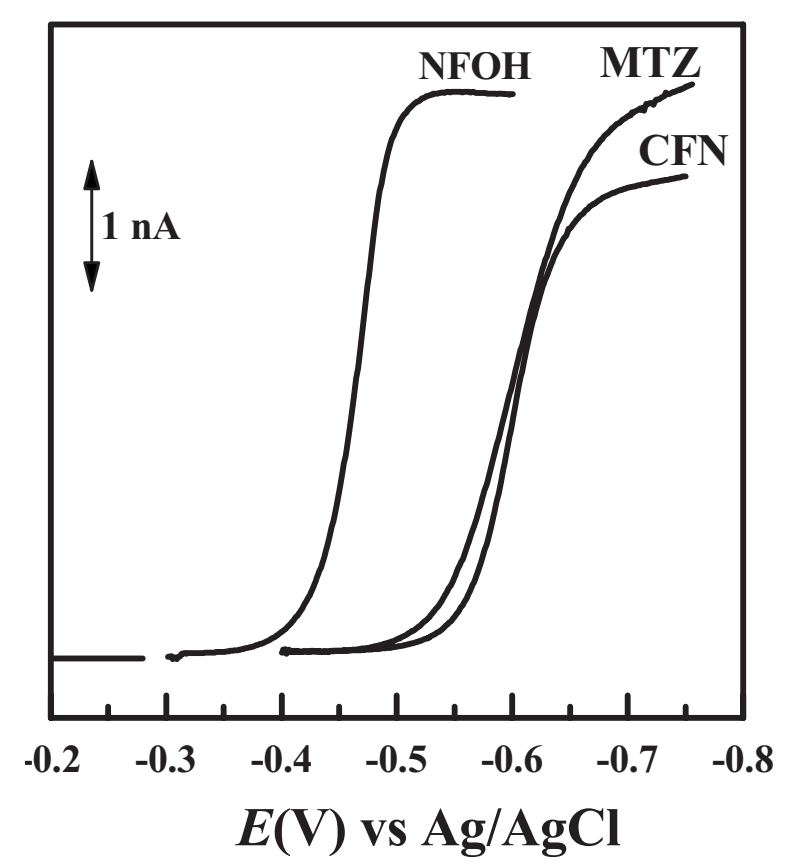

Figure 2. Linear-sweep voltammograms at carbon-fiber microelectrode of $1.0 \mathrm{mmol} \mathrm{L}{ }^{-1}$ nitrocompounds in aqueous solution at $\mathrm{pH} 7.4$ and scan rate $=5 \mathrm{mV} \mathrm{s}^{-1}$.

\section{Results and Discussion}

As already mentioned, NFOH was obtained by reaction with formaldehyde via a Mannich reaction. Consequently, it could be converted back to NF at physiological $\mathrm{pH} .{ }^{19}$ However, the conversion of NFOH to NF is extremely slow at $\mathrm{pH} 7.4$ (half-life of $134 \mathrm{~h}$ at $37^{\circ} \mathrm{C}$ ) but quite fast in acidic medium (half-life of $1.5 \mathrm{~h}$ at $\mathrm{pH}$ 1.2). ${ }^{5}$ Therefore, we hypothesize that there was no conversion of $\mathrm{NFOH}$ to NF during the electrochemical experiments at $\mathrm{pH}$ values higher than 8 because all solutions tested were freshly prepared before each voltammetric measurement.

The cyclic voltammogram of $\mathrm{NFOH}$ in aqueous media showed two reductive peaks corresponding to hydroxylamine (RNHOH) and amine $\left(\mathrm{RNH}_{2}\right)$ formation, usual for nitrofuran compounds. ${ }^{10-17} \mathrm{At}$ pH 7.4 and a scan rate of $0.1 \mathrm{~V} \mathrm{~s}^{-1}$, the -0.469 and $-0.951 \mathrm{~V}$ potential peak values were, respectively, registered. The number of electrons transferred during the reduction process was estimated by comparing the NFOH limiting currents with those obtained for MTZ and CFN at the same concentration. ${ }^{27-29}$ The electrochemical reduction for both latter drugs involves four electrons at $\mathrm{pH} 7.4 .^{12,13,16,17}$ As these nitro compounds and NFOH have similar diffusion coefficient values, the comparison of the limiting currents $\left(I_{\mathrm{L}}\right)$ obtained by linear-sweep voltammetry at microelectrodes ${ }^{29}$ is a good approximation of the number of electrons involved. Figure 2 shows the linear-sweep voltammograms of the studied nitro compounds using a carbon-fiber microelectrode. The $I_{\mathrm{L}}$ values are closely related $\left(I_{\mathrm{L}}\right.$ $\mathrm{NFOH} / I_{\mathrm{L}} \mathrm{MTZ}$ and $I_{\mathrm{L}} \mathrm{NFOH} / I_{\mathrm{L}} \mathrm{CFN}$ are close to 1 ), indicating that these compounds have similar reduction processes, involving the same number of electrons, which confirms the previously published results. ${ }^{16,17}$ Therefore, it can be assumed that the hydroxylamine derivative is the main product of $\mathrm{NFOH}$ voltammetric reduction.

As observed in Fig. 3, the NFOH reduction peak obtained in an acidic medium is split at $\mathrm{pH} \geq 7.20$. At this $\mathrm{pH}$, a shoulder appears around $-0.5 \mathrm{~V}$ and becomes a peak at $\mathrm{pH}>9.2$. A corresponding oxidation peak becomes visible at $\mathrm{pH}>7.58$. A similar voltammetric behavior was observed for 5-nitroimidazole under the same experimental conditions (results not shown). This reduction peak is 


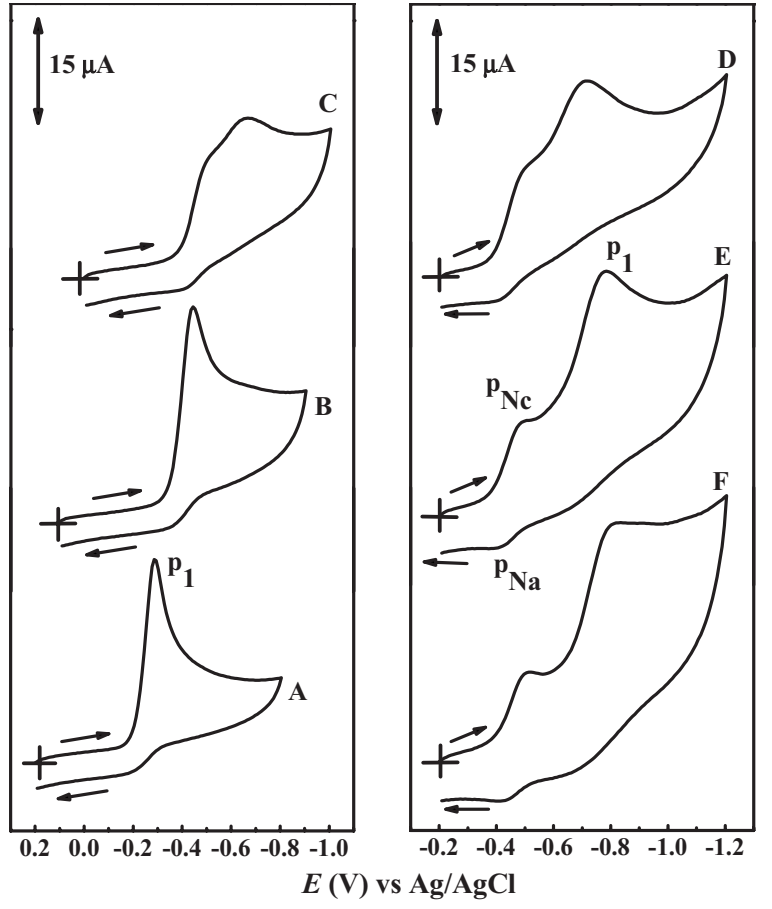

Figure 3. Cyclic voltammograms of $0.5 \mathrm{mmol} \mathrm{L}^{-1} \mathrm{NFOH}$ registered in several $\mathrm{pH}$ values in aqueous medium, using GCE with scan rate $=1.0 \mathrm{~V} \mathrm{~s}^{-1} . \mathrm{pH}$ : (A) 1.99, (B) 5.10, (C) 7.20, (D) 7.58, (E) 9.20, and (F) 12.0.

due to the reversible one-electron reduction to the radical anion and the other peak is due to the further three-electron reduction of the radical anion to the hydroxylamine $\mathrm{e}^{9,11}$

$$
\begin{gathered}
\mathrm{R}-\mathrm{NO}_{2}+1 \mathrm{e}^{-} \rightleftharpoons \mathrm{R}-\mathrm{NO}_{2}^{--} \\
\mathrm{R}_{-} \mathrm{NO}_{2}^{--}+3 \mathrm{e}^{-}+4 \mathrm{H}^{+} \rightarrow \mathrm{R}-\mathrm{NHOH}+\mathrm{H}_{2} \mathrm{O}
\end{gathered}
$$

Figure 4 clearly shows that the NFOH voltammetric reduction

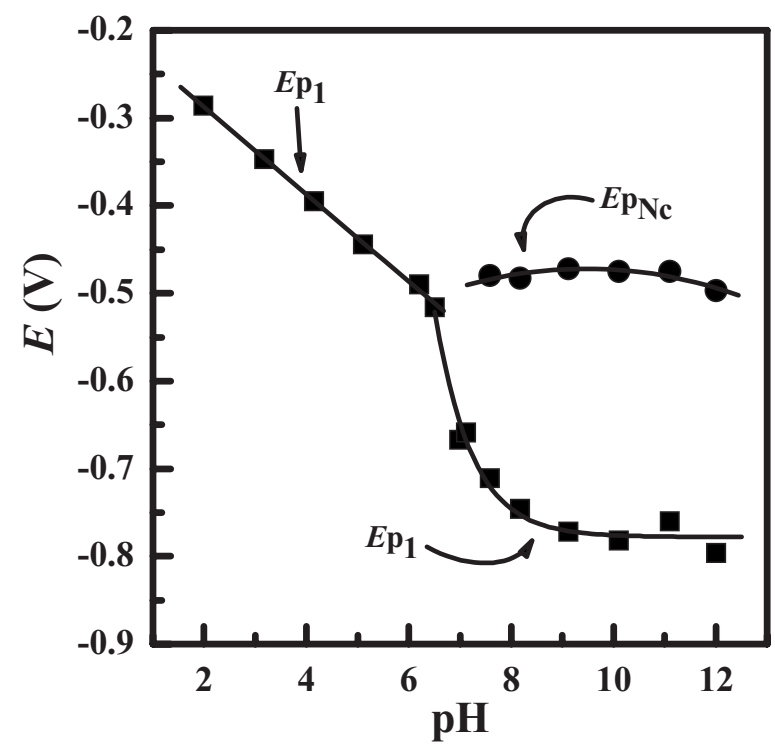

Figure 4. Change of peak potential with $\mathrm{pH}$ in aqueous medium using GCE and scan rate $=1.0 \mathrm{~V} \mathrm{~s}^{-1}$. $[\mathrm{NFOH}]=0.5 \mathrm{mmol} \mathrm{L} \mathrm{L}^{-1} . E \mathrm{p}_{1}$ corresponds to hydroxylamine derivative formation and $E \mathrm{p}_{\mathrm{Nc}}$ is the cathodic peak of the $\mathrm{R}-\mathrm{NO}_{2} / \mathrm{R}-\mathrm{NO}_{2}^{--}$couple.

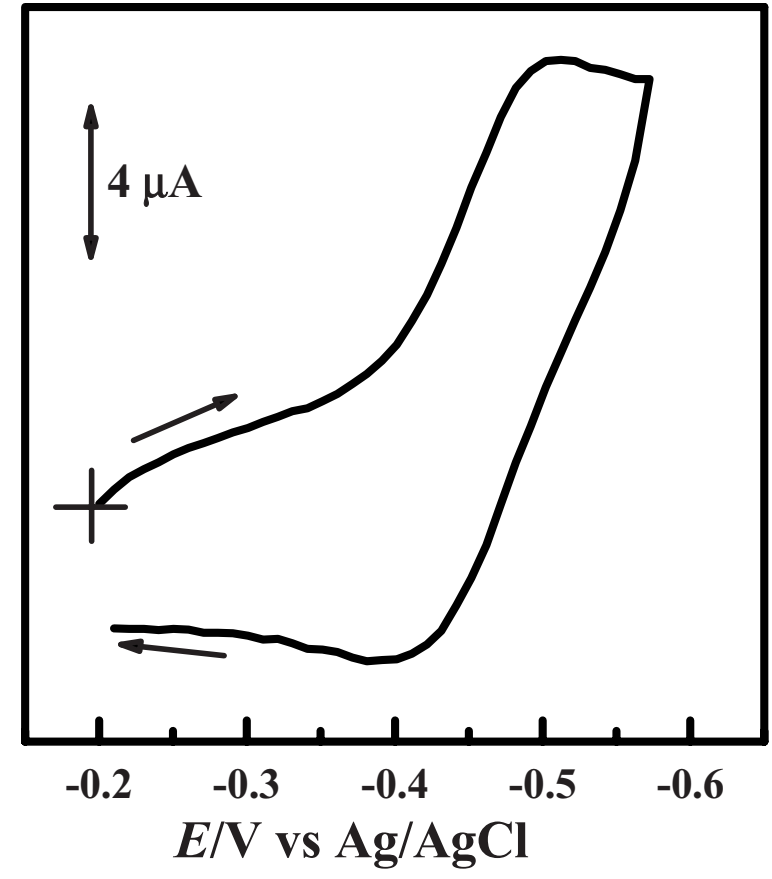

Figure 5. Cyclic voltammogram corresponding to $\mathrm{R}-\mathrm{NO}_{2} / \mathrm{R}-\mathrm{NO}_{2}^{\circ-}$ couple at $\mathrm{pH} 10.2$ and $[\mathrm{NFOH}]=0.5 \mathrm{mmol} \mathrm{L}{ }^{-1}$ using GCE, scan rate $=2.0 \mathrm{~V} \mathrm{~s}^{-1}$, and switching potential $=-0.57 \mathrm{~V}$.

is $\mathrm{pH}$ dependent. The $E \mathrm{p}_{1}$ values are linearly $\left(\Delta E \mathrm{p}_{1} / \Delta \mathrm{pH}\right.$ $=-49.7 \mathrm{mV} / \mathrm{pH}$ ) shifted to negative potential values in an acidic medium. However, it is evident that a distinct process occurs on the working electrode at $\mathrm{pH}$ values higher than 7.58 . The reduction peak $\left(E \mathrm{p}_{\mathrm{Nc}}\right)$ due to the one-electron reduction to the radical anion appears at more positive potentials. $E \mathrm{p}_{1}$, due to the three-electron reduction to the hydroxylamine, is shifted to more negative potentials with increasing $\mathrm{pH}$ but not linearly. In contrast, $E \mathrm{p}_{\mathrm{Nc}}$ does not change with $\mathrm{pH}$. Therefore, the potential difference between $E \mathrm{p}_{1}$ and $E \mathrm{p}_{\mathrm{Nc}}$ becomes larger as the proton availability decreases. As already proposed, ${ }^{30}$ the three-electron reduction step to the hydroxylamine most probably involves first the protonation of the radical anion, which is followed by further reduction of the radical. The shift of $E \mathrm{p}_{1}$ to more negative potentials in the case of the GCE might be due to competitive adsorption, preventing the nitro radical anion surface protonation. The performed comparisons with mercury ${ }^{14}$ and gold $^{30}$ electrodes confirm this behavior. Moreover, the voltammetric study of nitrofurans ${ }^{15}$ has demonstrated that the nitro radical anion was not sufficiently and kinetically stable to produce a couple using a mercury electrode in protic medium, even at alkaline $\mathrm{pH}$. The behavior herein described shows that the GCE polishing using diamond powder produced a similar effect to that observed in an aqueous medium after the alumina removal from the electrode surface by sonication in ethanol. ${ }^{16}$

Figure 5 shows the first reduction step cyclic voltammogram of $\mathrm{NFOH}$ at $\mathrm{pH} 10.2$, corresponding to the $\mathrm{R}-\mathrm{NO}_{2} / \mathrm{R}-\mathrm{NO}_{2}^{--}$couple, with $E \mathrm{p}_{\mathrm{Nc}}=-0.512 \mathrm{~V}$ and the reverse anodic peak with $E \mathrm{p}_{\mathrm{Na}}=$ $-0.391 \mathrm{~V}$. While the $E \mathrm{p}_{\mathrm{Nc}}$ values did not change with scan rate, the cathodic peak current $\left(\mathrm{I}_{\mathrm{N}_{\mathrm{Nc}}}\right)$ increased linearly with $v^{1 / 2}(0.3 \leq v$ $\leq 2 \mathrm{~V}$ ), indicating that the process is controlled by diffusion according to $I \mathrm{p}_{\mathrm{Nc}}(\mu \mathrm{A})=11.7 v^{1 / 2}\left(\mathrm{~V}^{1 / 2} \mathrm{~s}^{-1 / 2}\right) ; r=0.998$. Although the $\Delta E \mathrm{p}$ values are large, by applying the Randles-Ševčik equation ${ }^{27}$ $\left(I \mathrm{p}=-2.69 \times 10^{5} n^{3 / 2} A D^{1 / 2} C_{\mathrm{NFOH}} v^{1 / 2}\right)$ and using the NFOH diffusion coefficient predicted ${ }^{31}\left(6.72 \times 10^{-6} \mathrm{~cm}^{2} \mathrm{~s}^{-1}\right)$, the oneelectron participation can be estimated for the first reduction step, confirming the nitro radical anion formation. ${ }^{16-18}$

The radical kinetic stability was evaluated through the current 


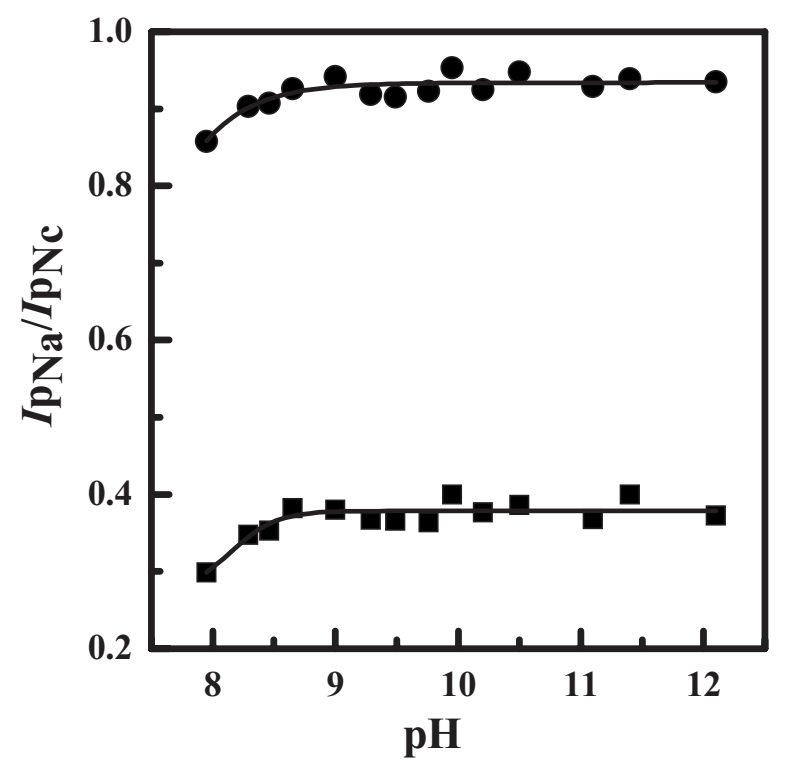

Figure 6. Effect of $\mathrm{pH}$ on current ratio corresponding to $\mathrm{R}-\mathrm{NO}_{2} / \mathrm{R}-\mathrm{NO}_{2}^{--}$ couple: $(\square) I \mathrm{p}_{\mathrm{Na} 0} / I \mathrm{p}_{\mathrm{Nc} 0}$ ratio with respect to the zero current axis and (O) $I \mathrm{p}_{\mathrm{Na}} / I \mathrm{p}_{\mathrm{Nc}}$ ratio with baseline correction. $[\mathrm{NFOH}]=0.5 \mathrm{mmol} \mathrm{L}^{-1}$, scan rate $=2.0 \mathrm{~V} \mathrm{~s}^{-1}$, and switching potential $=-0.57 \mathrm{~V}$.

ratio $\left(I \mathrm{p}_{\mathrm{Na}} / I \mathrm{p}_{\mathrm{Nc}}\right)^{27}$ analysis corresponding to the one-electron reversible couple due to the $\mathrm{R}-\mathrm{NO}_{2} / \mathrm{R}-\mathrm{NO}_{2}^{--}$redox system. Figure 6 shows that the kinetic stability increases between $\mathrm{pH} 8$ and 9 and remains constant at higher $\mathrm{pH}$ values. Due to the overlap of the current of the first peak with that of the second peak (formation of the hydroxylamine), the average value of $I \mathrm{p}_{\mathrm{Nc}}$ corresponds to about $97 \%$ of the real value taking into account the switching potential currents $\left(I_{\lambda}\right)$ and the baseline correction for $I \mathrm{p}_{\mathrm{Na}} / I \mathrm{p}_{\mathrm{Nc}}$ (Fig. 6).

The effects of the scan rate and drug concentration on the $I \mathrm{p}_{\mathrm{Na}} / I \mathrm{p}_{\mathrm{Nc}}$ ratio are presented in Fig. 7 and 8 , respectively. While the former shows that, as the scan rate is increased, the current ratio tends toward unity, yet the latter shows that the current ratio decreases as the NFOH concentration increases. These diagnostic cri-

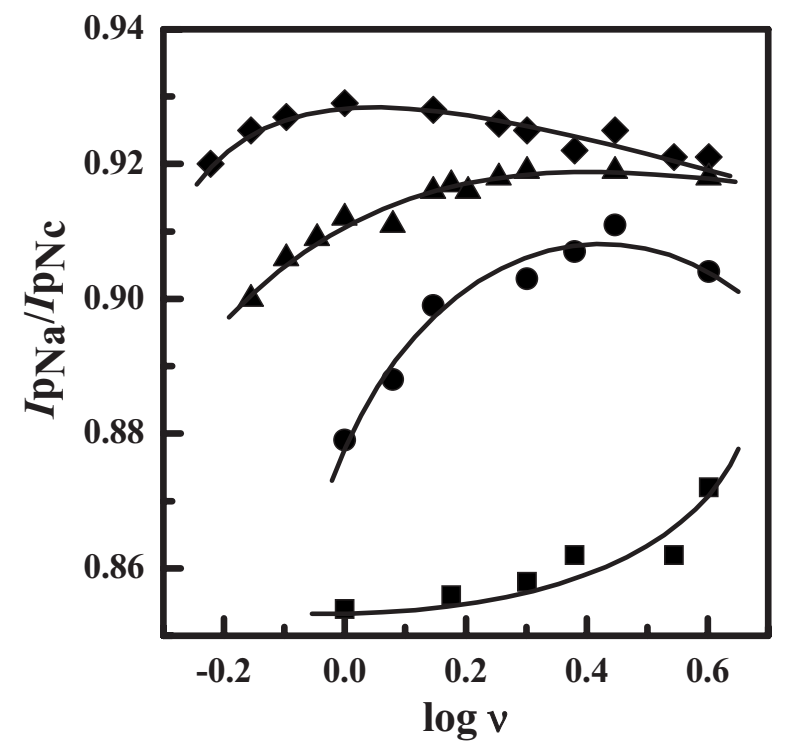

Figure 7. Relationship between $I \mathrm{p}_{\mathrm{Na}} / I \mathrm{p}_{\mathrm{Nc}}$ ratio and $\log v$ at several $\mathrm{pH}$

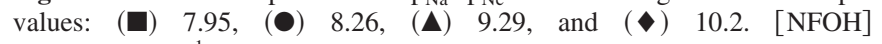
$=0.5 \mathrm{mmol} \mathrm{L}-1 ;-0.57 \leq$ switching potential $\leq-0.60 \mathrm{~V}$.

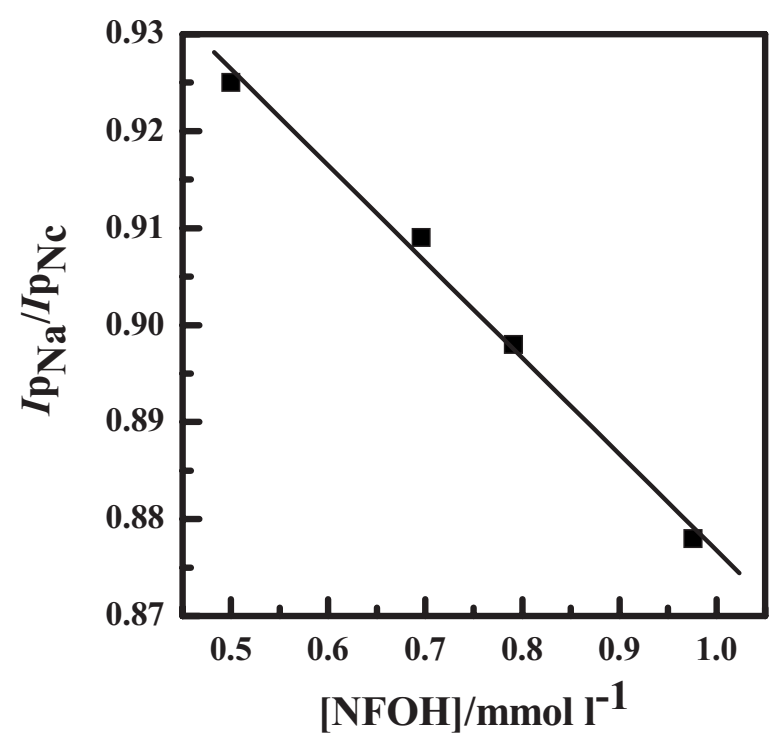

Figure 8. Variation of $I \mathrm{p}_{\mathrm{Na}} / I \mathrm{p}_{\mathrm{Nc}}$ ratio values with $\mathrm{NFOH}$ concentration at $\mathrm{pH}$ 10.2 using GCE. Scan rate $=2.0 \mathrm{~V} \mathrm{~s}^{-1}$; switching potential $=-0.57 \mathrm{~V}$.

teria fulfill the requirements for a coupled homogeneous electrode process, in which an irreversible chemical reaction follows a reversible charge-transfer step. Furthermore, this chemical irreversible reaction is considered second order, as the current ratio is not reagentconcentration dependent on the first-order reaction. ${ }^{11,27}$ The behavior described herein leads to a conclusion that NFOH undergoes an irreversible reaction of disproportionation after the nitro radical anion generation, as depicted in the overall mechanism below $^{9}$

$$
2 \mathrm{R}-\mathrm{NO}_{2}^{--}+2 \mathrm{H}^{+} \rightarrow \mathrm{R}-\mathrm{NO}_{2}+\mathrm{R}-\mathrm{NO}+\mathrm{H}_{2} \mathrm{O}
$$

As it is considered a second-order reaction, its rate constant $\left(k_{2}\right)$ can be determined by the Olmstead-Nicholson method. ${ }^{26}$ Recently, this mechanism was very well described by Squella et al. ${ }^{11}$ for several nitroheterocyclic compounds. Figure 9 shows the plots, based on this theory, where a linear relationship between the kinetic parameters, $\omega$ vs $\tau$, is obtained at different $\mathrm{pH}$ values. Table I presents

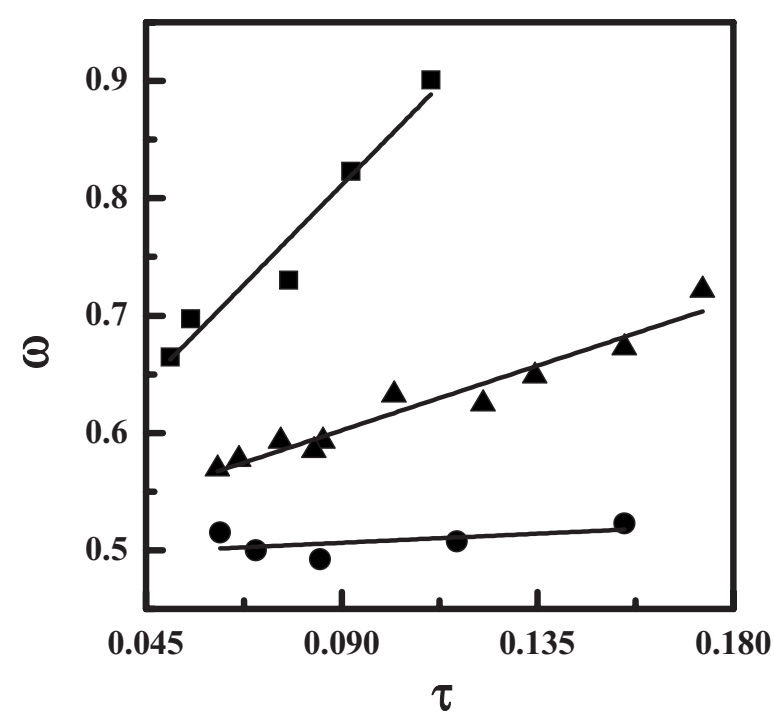

Figure 9. Plot of the kinetic parameter, $\omega$, vs the time constant, $\tau$, for $[\mathrm{NFOH}]=0.5 \mathrm{~m} \mathrm{~mol}^{-1}$ at different $\mathrm{pH}$ values: $(\boldsymbol{\square}) 8.26,(\mathbf{\Delta}) 9.29,(\mathbf{O})$ $10.2 ;-0.57 \mathrm{~V} \leq$ switching potential $\leq-0.60 \mathrm{~V}$. 


\begin{tabular}{|c|c|c|}
\hline $\mathrm{pH}$ & $\begin{array}{c}k_{2} \times 10^{-3} \\
\left(\mathrm{~L} \mathrm{~mol}^{-1} \mathrm{~s}^{-1}\right)\end{array}$ & $\begin{array}{c}t_{1 / 2} \\
(\mathrm{~s})\end{array}$ \\
\hline 8.29 & 6.07 & 0.33 \\
\hline 9.29 & 2.06 & 0.97 \\
\hline 10.2 & 1.44 & 1.4 \\
\hline
\end{tabular}

three examples of $k_{2}$, showing that the nitro radical anion stabilization improves in alkaline medium, which confirms that the $\mathrm{R}-\mathrm{NO}_{2}^{--}$ disproportionation is slower at higher $\mathrm{pH}$ values, as stated by the calculated half-time life $\left(t_{1 / 2}\right)$. Compared with other nitrofuran compounds, ${ }^{11}$ the $k_{2}$ values obtained for NFOH in this work are around 1 order of magnitude larger than those registered in an aprotic or mixed medium. From these aspects, it is possible to infer that the nitro radical anion decay is facilitated in a protic medium. As there are no indications that the $\mathrm{R}-\mathrm{NO}_{2}^{-}$itself reacts in water $(k$ $\approx 0),{ }^{9}$ the protic medium can favor the nitro radical anion decay providing enough protons for the $\mathrm{R}-\mathrm{NO}_{2} \mathrm{H}^{\bullet}$ formation, facilitating the fast protonation reaction between the conjugate base $\mathrm{R}-\mathrm{NO}_{2}^{--}$ and the neutral radical formed, as depicted below ${ }_{9,32}$

$$
\mathrm{R}-\mathrm{NO}_{2} \mathrm{H}^{\bullet}+\mathrm{R}-\mathrm{NO}_{2}^{-}\left(+\mathrm{H}^{+}\right) \rightarrow \mathrm{R}-\mathrm{NO}_{2}+\mathrm{R}-\mathrm{NO}\left(+\mathrm{H}^{+}\right)
$$

Based on the discussion above, even though the nitro radical anion is less kinetically stable in an aqueous/protic medium than in an aprotic/mixed medium (for instance, 60\% dimethylformamide and $40 \% \mathrm{H}_{2} \mathrm{O}$ ), it is stable enough to carry out quantitative studies on its interactions with biological targets under experimental conditions as close as possible to the biological system. ${ }^{11}$

\section{Conclusions}

$\mathrm{NFOH}$ was reduced in an acidic medium at a GCE, producing only one reduction peak involving four electrons due to the hydroxylamine derivative formation. Furthermore, the generation and observation of the nitro radical anion in an alkaline aqueous medium were possible because of its slow protonation. This work also clearly indicates that the GCE surface activation through polishing with diamond powder contributed to the kinetic stability of the nitro radical anion due to the hydrophobic properties of the interface, hindering or even suppressing the radical anion protonation in the diffusion layer. This behavior corroborates the previous hypothesis ${ }^{16}$ that the acid-base properties of the alumina on the GCE surface does facilitate deprotonation of $\mathrm{R}-\mathrm{NO}_{2}^{--}$.

Therefore, the study of the nitro radical anion generation in an aqueous medium may allow us to increase our knowledge about biological targets, leading to a better comprehension of the nitroheterocyclic compounds' mechanism and its charge-transfer process in experimental conditions close to the biological system, which will certainly contribute to the development of potential antichagasic derivatives.

\section{Acknowledgments}

We thank FAPESP for the financial support (process no. 01/ 01192-3 and no. 03/10763-0) and for the postdoctor fellowship to M.A.L.-S. (process no. 01/09418-0), Capes-Prodoc fellowship to C.M.S.M. (process no. 00019-03-8), and CNPq research fellowship to E.I.F.

\section{References}

1. WHO, Chagas Disease: Strategic Direction for Research. Disease Burden and Epidemiological Trends, http://www.who.int/tdr/diseases/chagas/direction, last accessed July 2007.

2. J. R. Coura and S. L. de Castro, Mem. Inst. Oswaldo Cruz, 97, 3 (2002).

3. H. Cerecetto, R. Di Maio, M. González, M. Risso, G. Sagrera, G. Seoane, A. Denicola, G. Peluffo, C. Quijano, A. O. M. Stoppani, et al., Eur. J. Med. Chem., 35, $343(2000)$.

4. V. Martinez-Merino and H. Cerecetto, Bioorg. Med. Chem., 9, 1025 (2001).

5. M. C. Chung, R. V. C. Guido, T. F. Martinelli, M. F. Gonçalves, M. C. Polli, K. C. A. Botelho, E. A. Varanda, W. Colli, M. T. M. Miranda, and E. I. Ferreira, Bioorg. Med. Chem., 11, 4779 (2003).

6. C. Viodé, C. N. Albuquerque, G. Chauvière, C. Houée-Lévin, and J. Périe, New J. Chem., 21, 1331 (1997).

7. K. Blumenstiel, R. Schöneck, V. Yardley, S. L. Croft, and R. L. Krauth-Siegel, Biochem. Pharmacol., 58, 1791 (1999).

8. J. H. Tocher, Gen. Pharmacol., 28, 485 (1997).

9. P. Wardman, Environ. Health Perspect., 64, 309 (1985).

10. J. Rozenski, C. J. De Ranter, and H. Verplanken, Quant. Struct.-Act. Relat., 14, 134 (1995).

11. J. A. Squella, S. Bollo, and L. J. Nuñez-Vergara, Curr. Org. Chem., 9, 565 (2005)

12. A. Morales, M. I. Toral, and P. Richter, Analyst (Cambridge, U.K.), 109, 633 (1984).

13. A. Morales, P. Richter, and M. I. Toral, Analyst (Cambridge, U.K.), 112, 965 (1987).

14. T. Symons, J. H. Tocher, D. A. Tocher, and D. I. Edwards, Free Radical Res. Commun., 14, 33 (1991).

15. S. Bollo, L. J. Nuñez-Vergara, C. Martinez, G. Chauviere, J. Périe, and J. A. Squella, Electroanalysis, 15, 19 (2003).

16. M. A. La-Scalea, C. M. S. Menezes, M. S. S. Julião, M. C. Chung, S. H. P. Serrano, and E. I. Ferreira, J. Braz. Chem. Soc., 16, 774 (2005).

17. M. S. S.Julião, E. C. Almeida, M. A. La-Scalea, N. G. Ferreira, R. G. Compton, and S. H. P. Serrano, Electroanalysis, 17, 269 (2005).

18. M. S. S. Julião, E. I. Ferreira, N. G. Ferreira, and S. H. P. Serrano, Electrochim. Acta, 51, 5080 (2006)

19. H. Bundgaard, in Design of Prodrugs, H. Bundgaard, Editor, p. 1, Elsevier, Amsterdam (1985).

20. M. F. Gonçalves, M. C. Chung, W. Colli, M. T. M. Miranda, and E. I. Ferreira, Rev. Soc. Bras. Med. Trop., 27, 164 (1994).

21. C. F. Barbosa, E. S. Okuda, M. C. Chung, E. I. Ferreira, and R. M. B. Cicarelli, Braz. J. Med. Biol. Res., 40, 33 (2007).

22. R. Grillo, N. F. S. Melo, C. M. Moraes, A. H. Rosa, J. A. F. Roveda, C. M. S Menezes, E. I. Ferreira, and L. F. Fraceto, J. Biol. Phys., 33, 445 (2007).

23. R. Grillo, N. F. S. Melo, C. M. Moraes, R. Lima, C. M. S. Menezes, E. I. Ferreira, A. H. Rosa, and L. F. Fraceto, J. Pharm. Biomed. Anal., 47, 295 (2008).

24. J. Lurie, Handbook of Analytical Chemistry, Mir, Moscow (1978).

25. A. C. Doriguetto, C. H. T. P. Silva, J. Ellena, G. H. G. Trossini, M. C. Chung, and E. I. Ferreira, Acta Crystallogr., Sect. E: Struct. Rep. Online, 61, o2099 (2005).

26. M. L. Olmstead and R. S. Nicholson, Anal. Chem., 41, 862 (1969).

27. A. J. Bard and L. R. Faulkner, Electrochemical Methods, John Wiley \& Sons, New York (2001).

28. F. Belal, A. Al-Majed, and S. Julkhuf, J. Pharm. Biomed. Anal., 31, 989 (2003).

29. R. Müller, L. Lamberts, and M. Evers, J. Electroanal. Chem., 401, 183 (1996).

30. P. C. Mandal, J. Electroanal. Chem., 570, 55 (2004).

31. M. A. La-Scalea, C. M. S. Menezes, and E. I. Ferreira, J. Mol. Struct: THEOCHEM, 730, 111 (2005).

32. J. Carbajo, S. Bollo, L. J. Nuñez-Vergara, A. Campero, and J. A. Squela, J. Electroanal. Chem., 531, 187 (2002). 